\title{
Relationship between lipid profiles and kidney function in patients with type 1 diabetes
}

\author{
N. Tolonen • C. Forsblom • L. Thorn • J. Wadén • \\ M. Rosengård-Bärlund $\cdot$ M. Saraheimo $\cdot$ O. Heikkilä • \\ K. Pettersson-Fernholm • M.-R. Taskinen • \\ P.-H. Groop • FinnDiane Study Group
}

Received: 27 May 2007 / Accepted: 10 July 2007 / Published online: 10 November 2007

(C) Springer-Verlag 2007

\begin{abstract}
Aims/hypothesis We studied the relationship between the lipid profile, estimated GFR (eGFR) and AER in patients with type 1 diabetes. We also assessed the association between the lipid profile and glycaemic control, obesity and hypertension in an environment free of manifest renal disease, as well as exploring how well the patients would have achieved the targets set in international guidelines.

Methods A total of 2,927 adult patients who had type 1 diabetes and for whom lipid profiles were available were included from people participating in the nationwide, multicentre Finnish Diabetic Nephropathy Study (FinnDiane). eGFR was determined using the Cockcroft-Gault formula adjusted for body surface area.

Results Patients with impaired renal function (eGFR $<60 \mathrm{ml} \mathrm{m^{-1 }} 1.73 \mathrm{~m}^{-2}$ ) had higher total cholesterol,
\end{abstract}

Electronic supplementary material The online version of this article (doi:10.1007/s00125-007-0858-y) contains supplementary material, which is available to authorised users.

N. Tolonen · C. Forsblom · L. Thorn · J. Wadén ·

M. Rosengård-Bärlund $\cdot$ M. Saraheimo $\cdot$ O. Heikkilä •

K. Pettersson-Fernholm $\cdot$ P.-H. Groop $(\bowtie)$

Folkhälsan Institute of Genetics, Folkhälsan Research Center, Biomedicum Helsinki (C318b), University of Helsinki,

Haartmaninkatu 8, P.O. Box 63, 00014 Helsinki, Finland

e-mail: per-henrik.groop@helsinki.fi

N. Tolonen $\cdot$ C. Forsblom $\cdot$ L. Thorn $\cdot$ J. Wadén •

M. Rosengård-Bärlund · M. Saraheimo • O. Heikkilä •

K. Pettersson-Fernholm • P.-H. Groop

Division of Nephrology, Department of Medicine,

Helsinki University Central Hospital,

Helsinki, Finland

M.-R. Taskinen

Division of Cardiology, Department of Medicine,

Helsinki University Central Hospital,

Helsinki, Finland triacylglycerol and apolipoprotein B, and lower HDLcholesterol concentrations than patients with normal renal function (eGFR $>90 \mathrm{ml} \mathrm{min}^{-1} 1.73 \mathrm{~m}^{-2}$ ) or mildly impaired renal function (eGFR 60-90 ml min $\left.{ }^{-1} 1.73 \mathrm{~m}^{-2}\right)(p<0.001$ for all associations). In type 1 diabetic patients without manifest renal disease, similar adverse lipid profiles could be observed in those who were overweight or obese and in those who had intermediate or poor glycaemic control or hypertension. In all the different patient groups 14 to $43 \%$ would have achieved the recommended target of $<2.6 \mathrm{mmol} / 1$ for LDL-cholesterol.

Conclusions/interpretation Multiple lipid abnormalities are not only present in type 1 diabetic patients with an abnormal AER, but also in those with impaired renal function. In patients without manifest renal disease, obesity, glycaemic control or hypertension were associated with an adverse lipid profile. A substantial number of patients studied would have exceeded the targets set by international guidelines, particularly the targets for LDL-cholesterol.

Keywords Albumin excretion rate - Apolipoprotein · BMI · Estimated GFR $\cdot \mathrm{HbA}_{1 \mathrm{c}} \cdot$ Hypertension $\cdot$ Lipid profile .

Renal disease $\cdot$ Renal function $\cdot$ Type 1 diabetes

$\begin{array}{ll}\text { Abbreviations } \\ \text { Apo } & \text { apolipoprotein } \\ \text { eGFR } & \text { estimated glomerular filtration rate } \\ \text { FinnDiane } & \text { Finnish Diabetic Nephropathy Study } \\ \text { MDRD } & \text { modification of diet in renal disease }\end{array}$

\section{Introduction}

Diabetes and dyslipidaemia are well-known independent risk factors for cardiovascular disease. Although patients 
with type 1 diabetes but without nephropathy have similar or even more favourable lipid profiles than non-diabetic individuals they still have a fourfold higher mortality from cardiovascular disease [1]. Notably, patients with type 1 diabetes and nephropathy have a tenfold greater risk of cardiovascular disease compared with those without nephropathy [2]. Microalbuminuria is a predictor of diabetic nephropathy and cardiovascular disease. In fact elevated AER is a continuous cardiovascular risk factor since even a mild increase within the normal range predicts cardiovascular risk [3], similarly to lipid variables, which also show a continuous relationship with cardiovascular disease without any apparent thresholds [4].

Earlier studies have shown that multiple lipid abnormalities cluster in incipient or overt diabetic nephropathy [5-7]. However, more recent larger cohort studies have not been able to replicate all these findings after adjusting for confounding variables [8]. Dyslipidaemia not only promotes cardiovascular risk, but may also play a role in the progression of diabetic nephropathy [9]. However, it is not yet clear whether the lipid abnormalities precede or coincide with the increase in AER.

In general, an increase in AER is paralleled by a decrease in GFR, although some patients with normal AER may already have a decreased GFR together with more advanced diabetic glomerular lesions [10]. So far data on the association between early changes in GFR and lipid disturbances in patients with type 1 diabetes are limited. Therefore, we studied the relationship between lipid variables, estimated GFR (eGFR) and AER in a large cohort of patients with type 1 diabetes. We also explored the effect of glycaemic control, obesity and hypertension on the lipid profile in type 1 diabetic patients with normal AER and eGFR $>60 \mathrm{ml} \mathrm{min}^{-1}$ $1.73 \mathrm{~m}^{-2}$, a cohort free from the confounding effect of manifest renal disease. Finally, we explored how well patients with type 1 diabetes would have achieved the targets of international guidelines with regard to both LDL- and HDLcholesterol, and triacylglycerol.

\section{Methods}

Study participants This report presents cross-sectional data from the baseline visit of patients who participated in the Finnish Diabetic Nephropathy Study (FinnDiane), a nationwide, multicentre study. The aim of the FinnDiane Study is to identify risk factors that play a role in the development and progression of microvascular and macrovascular complications in type 1 diabetes. Adult patients with type 1 diabetes from more than 70 hospitals and primary healthcare centres all over Finland were consecutively asked to participate. The study protocol follows the Declaration of Helsinki and has been approved by the local ethics committee of each participating study centre. All patients gave their written informed consent before participation.

Diagnosis and laboratory measurements Type 1 diabetes was defined as an onset of diabetes before the age of 35 years, with permanent insulin treatment required within 1 year of diagnosis. Complete lipid profiles were obtained from 3,448 patients. Patients with end-stage renal disease $(n=231)$ and patients with unclassified renal status $(n=290)$ were excluded from the study. Altogether, 2,927 patients with diabetes were used in the analyses, while 197 nondiabetic participants served as a control group. Patients taking lipid-lowering agents $(n=272)$ and patients without data for calculation of estimated GFR $(n=77)$ were excluded from the respective analyses. Data were obtained from patients who participated in the FinnDiane study between 1994 and 2004. All serum lipid and lipoprotein concentrations were measured from fasting blood samples at the research laboratory of Helsinki University Central Hospital, Division of Cardiology, Finland. Total cholesterol and triacylglycerol were determined enzymatically using an autoanalyser (Cobas Mira or Mira Plus; ABX Diagnostics, Montpellier, France). Total HDL- and $\mathrm{HDL}_{3}$-cholesterol were determined enzymatically using an assay reader (HTS 7000 Plus Bio; Perkin Elmer, Wellesley, MA, USA). $\mathrm{HDL}_{2}$-cholesterol was calculated by subtracting $\mathrm{HDL}_{3}$-cholesterol from total HDL-cholesterol. LDL-cholesterol was calculated with the Friedewald formula [11]. Serum apolipoprotein (Apo) A-I, A-II and B concentrations were determined by immunoassay (Orion Diagnostica, Espoo, Finland). Cut off values based on the recommendation of the American Diabetes Association [12] were: LDL-cholesterol $\geq 2.6 \mathrm{mmol} / 1$, triacylglycerol $\geq 1.7 \mathrm{mmol} / 1$ and HDL-cholesterol $\leq 1.0 \mathrm{mmol} / 1$ for men and $\leq 1.3 \mathrm{mmol} / 1$ for women.

eGFR was calculated on the basis of a single serum creatinine measurement using the Cockcroft-Gault formula adjusted for body surface area [13]. Classification of renal function on the basis of eGFR was as follows: normal $>90 \mathrm{ml} \mathrm{min}^{-1} 1.73 \mathrm{~m}^{-2}$, mildly impaired 60-90 $\mathrm{ml} \mathrm{min}^{-1}$ $1.73 \mathrm{~m}^{-2}$ and impaired $<60 \mathrm{ml} \mathrm{min}{ }^{-1} 1.73 \mathrm{~m}^{-2}$. Based on the AER in at least two of three consecutive overnight or $24 \mathrm{~h}$ urine collections, patients were divided into the following three groups: normal AER $<20 \mu \mathrm{g} / \mathrm{min}$ or $<30 \mathrm{mg} / 24 \mathrm{~h}$, microalbuminuria AER $20-200 \mu \mathrm{g} / \mathrm{min}$ or $30-300 \mathrm{mg} / 24 \mathrm{~h}$ and macroalbuminuria AER $>200 \mu \mathrm{g} / \mathrm{min}$ or $>300 \mathrm{mg} / 24 \mathrm{~h}$. In addition to the urine collections for classification, AER (24 h) was also measured centrally with an immunoturbidimetric method; the result of this measurement was used in the linear regression analyses. $\mathrm{HbA}_{1 \mathrm{c}}$ was determined locally at each centre by standardised immunoassays and patients were divided into three groups with regard to glycaemic control: good $\mathrm{HbA}_{1 \mathrm{c}}<7.5 \%$, intermediate $\mathrm{HbA}_{1 \mathrm{c}} 7.5-9.0 \%$ and poor $\mathrm{HbA}_{1 \mathrm{c}}>9.0 \%$. Data on medication and diabetic micro- and 
macrovascular complications were obtained using a standardised questionnaire, which was completed by the patients' attending physician on the basis of medical records. BMI was calculated as weight $/$ height $^{2}\left(\mathrm{~kg} / \mathrm{m}^{2}\right)$. BMI $<25 \mathrm{~kg} / \mathrm{m}^{2}$ was classified as normal, $25-30 \mathrm{~kg} / \mathrm{m}^{2}$ as overweight and $>30 \mathrm{~kg} / \mathrm{m}^{2}$ as obesity. Blood pressure was measured twice at $2 \mathrm{~min}$ intervals in the sitting position after a $10 \mathrm{~min}$ rest and the mean value was used in the analyses. Hypertension was defined as the use of antihypertensive medication or systolic/diastolic blood pressure higher than $130 / 80 \mathrm{mmHg}$. A cardiovascular event was defined as a history of myocardial infarction, stroke (cerebral infarction or intracerebral haemorrhage) or amputation. Coronary heart disease was defined as myocardial infarction, coronary revascularisation or regular use of long-acting nitroglycerin. Current smoking was defined as smoking at least one cigarette per day.

Statistical analyses All analyses were performed using SPSS 12.0.1 for Windows (SPSS, Chicago, IL, USA). Data for normally distributed values are presented as means \pm SD and data for non-normally distributed values as medians with interquartile range. Statistically significant differences between groups were analysed with ANOVA, MannWhitney $U$ test or Kruskal-Wallis test as appropriate. Categorical variables were analysed using Pearson's $\chi^{2}$ test.
Values of $p$ for comparison between groups were adjusted for age, sex and BMI, except in the comparison between the BMI groups where $p$ values were adjusted only for age and sex. Multiple linear regression analyses were performed with either eGFR or AER as the dependent variable. Non-normally distributed values (triacylglycerol and AER) were logarithmically transformed before inclusion in the models. A more stringent level of significance, $p<0.01$, was chosen to correct for multiple testing, except for the multiple linear regression analyses where $p<0.05$ denoted statistical significance.

\section{Results}

Lipid profile by renal function Clinical characteristics of the patients grouped by eGFR and the control group are presented in Table 1. Table 2 shows the associations between renal function and lipid profiles. Patients with impaired renal function had higher total cholesterol, LDL-cholesterol, triacylglycerol and ApoB, as well as lower HDL-cholesterol levels than patients with normal or mildly impaired renal function $(p<0.001$ for all). In contrast, the lipid profiles of patients with normal or mildly impaired renal function were almost similar. In comparison with the non-diabetic control participants, diabetic patients with normal renal function had

Table 1 Clinical characteristics grouped by eGFR

\begin{tabular}{|c|c|c|c|c|}
\hline & eGFR $>90$ & eGFR 60-90 & eGFR $<60$ & $\begin{array}{l}\text { Non-diabetic } \\
\text { control group }\end{array}$ \\
\hline$N$ & 1,570 & 959 & 321 & 197 \\
\hline Men $(\%)$ & 57 & 42 & 55 & 46 \\
\hline Age (years) & $31.5 \pm 9.5$ & $42.1 \pm 10.6$ & $46.3 \pm 11.1$ & $35.8 \pm 11.2$ \\
\hline Age at onset (years) & $14.3 \pm 8.3$ & $15.7 \pm 8.8$ & $14.1 \pm 8.1$ & - \\
\hline Diabetes duration (years) & $17.2 \pm 9.8$ & $26.4 \pm 11.2$ & $32.2 \pm 9.1$ & - \\
\hline Systolic blood pressure (mmHg) & $129 \pm 15$ & $133 \pm 18$ & $147 \pm 20$ & $126 \pm 14$ \\
\hline Diastolic blood pressure $(\mathrm{mmHg})$ & $79 \pm 10$ & $79 \pm 9$ & $81 \pm 11$ & $77 \pm 8$ \\
\hline BMI $\left(\mathrm{kg} / \mathrm{m}^{2}\right)$ & $25.5 \pm 3.7$ & $24.6 \pm 3.0$ & $25.0 \pm 3.8$ & $23.8 \pm 2.8$ \\
\hline \multicolumn{5}{|l|}{ WHR } \\
\hline Men & $0.90 \pm 0.07$ & $0.91 \pm 0.07$ & $0.94 \pm 0.08$ & $0.92 \pm 0.06$ \\
\hline Women & $0.81 \pm 0.07$ & $0.81 \pm 0.07$ & $0.82 \pm 0.06$ & $0.83 \pm 0.05$ \\
\hline $\mathrm{HbA}_{1 \mathrm{c}}(\%)$ & $8.5 \pm 1.5$ & $8.3 \pm 1.4$ & $8.9 \pm 1.6$ & $5.6 \pm 0.35$ \\
\hline Serum creatinine $(\mu \mathrm{mol} / \mathrm{l})$ & $78 \pm 13$ & $95 \pm 15$ & $215 \pm 137$ & $76 \pm 14$ \\
\hline $\operatorname{AER}(m g / 24$ h) & $10(6-24)$ & $11(6-53)$ & $330(54-1281)$ & - \\
\hline Macroalbuminuria (\%) & 6 & 17 & 79 & - \\
\hline Cardiovascular event (\%) & 2 & 7 & 26 & 0 \\
\hline Coronary heart disease $(\%)$ & 1 & 5 & 16 & 0 \\
\hline Retinal laser treatment $(\%)$ & 17 & 38 & 80 & - \\
\hline Current smokers $(\%)$ & 27 & 22 & 23 & 12 \\
\hline Antihypertensive medication (\%) & 20 & 43 & 92 & 4 \\
\hline Lipid-lowering agents (\%) & 4 & 10 & 29 & 0 \\
\hline
\end{tabular}

Data are means $\pm \mathrm{SD}$, median (interquartile range) or $\%$ eGFR is given in $\mathrm{ml} \mathrm{min}{ }^{-1} 1.73 \mathrm{~m}^{-2}$ 
Table 2 The lipid profile in patients with type 1 diabetes subdivided by eGFR and AER

\begin{tabular}{|c|c|c|c|c|c|c|c|}
\hline & eGFR >90 & $\begin{array}{l}\text { eGFR } \\
60-90\end{array}$ & eGFR $<60$ & $\begin{array}{l}\text { Normal } \\
\text { AER }\end{array}$ & Microalbuminuria & Macroalbuminuria & $\begin{array}{l}\text { Non-diabetic } \\
\text { control }\end{array}$ \\
\hline$n$ & 1,505 & 857 & 228 & 1,848 & 412 & 395 & 197 \\
\hline $\begin{array}{l}\text { Total cholesterol } \\
(\mathrm{mmol} / \mathrm{l})\end{array}$ & $4.80 \pm 0.95$ & $5.04 \pm 0.84$ & $5.37 \pm 1.10^{\mathrm{b}, \mathrm{c}}$ & $4.80 \pm 0.89$ & $5.02 \pm 0.91^{\mathrm{e}}$ & $5.41 \pm 1.03^{\mathrm{e}, \mathrm{f}}$ & $4.76 \pm 0.92$ \\
\hline $\begin{array}{l}\text { LDL-cholesterol } \\
(\mathrm{mmol} / \mathrm{l})\end{array}$ & $2.98 \pm 0.86$ & $3.14 \pm 0.80$ & $3.40 \pm 0.92^{\mathrm{b}, \mathrm{c}}$ & $2.97 \pm 0.82$ & $3.13 \pm 0.83$ & $3.50 \pm 0.88^{\mathrm{e}, \mathrm{f}}$ & $2.77 \pm 0.83^{\mathrm{b}, \mathrm{d}}$ \\
\hline $\begin{array}{l}\text { HDL-cholesterol } \\
(\mathrm{mmol} / \mathrm{l})\end{array}$ & $1.27 \pm 0.34$ & $1.40 \pm 0.38$ & $1.19 \pm 0.39^{\mathrm{b}, \mathrm{c}}$ & $1.34 \pm 0.37$ & $1.31 \pm 0.39$ & $1.17 \pm 0.34^{\mathrm{e}, \mathrm{f}}$ & $1.54 \pm 0.30^{\mathrm{b}, \mathrm{e}}$ \\
\hline $\begin{array}{l}\mathrm{HDL}_{2-} \text { cholesterol } \\
(\mathrm{mmol} / \mathrm{l})\end{array}$ & $0.50 \pm 0.23$ & $0.61 \pm 0.27$ & $0.49 \pm 0.26^{\mathrm{b}, \mathrm{c}}$ & $0.55 \pm 0.25$ & $0.53 \pm 0.25$ & $0.46 \pm 0.24^{\mathrm{e}, \mathrm{f}}$ & $0.47 \pm 0.22^{\mathrm{b}, \mathrm{e}}$ \\
\hline $\begin{array}{l}\mathrm{HDL}_{3} \text {-cholesterol } \\
(\mathrm{mmol} / \mathrm{l})\end{array}$ & $0.77 \pm 0.18$ & $0.79 \pm 0.21$ & $0.71 \pm 0.20^{\mathrm{b}, \mathrm{c}}$ & $0.79 \pm 0.20$ & $0.78 \pm 0.21$ & $0.71 \pm 0.18^{\mathrm{e}, \mathrm{f}}$ & $1.07 \pm 0.15^{\mathrm{b}, \mathrm{e}}$ \\
\hline $\begin{array}{l}\text { Triacylglycerol } \\
(\mathrm{mmol} / \mathrm{l})\end{array}$ & $\begin{array}{l}1.00 \\
(0.76-1.41)\end{array}$ & $\begin{array}{l}0.95 \\
(0.74-1.28)\end{array}$ & $\begin{array}{l}1.38 \\
(1.04-2.10)^{\mathrm{b}, \mathrm{c}}\end{array}$ & $\begin{array}{l}0.95 \\
(0.73-1.28)\end{array}$ & $\begin{array}{l}1.04 \\
\quad(0.81-1.53)^{\mathrm{e}}\end{array}$ & $\begin{array}{l}1.37 \\
(0.99-1.98)^{\mathrm{e}, \mathrm{f}}\end{array}$ & $\begin{array}{l}0.88 \\
(0.69-1.21)\end{array}$ \\
\hline ApoA-I (g/l) & $1.36 \pm 0.21$ & $1.44 \pm 0.22^{\mathrm{a}}$ & $1.37 \pm 0.23^{\mathrm{c}}$ & $1.39 \pm 0.22$ & $1.40 \pm 0.22$ & $1.38 \pm 0.23$ & $1.40 \pm 0.29$ \\
\hline ApoA-II (g/l) & $0.34 \pm 0.09$ & $0.33 \pm 0.08$ & $0.32 \pm 0.08^{\mathrm{a}}$ & $0.33 \pm 0.09$ & $0.35 \pm 0.09$ & $0.33 \pm 0.08$ & $0.36 \pm 0.07^{\mathrm{e}}$ \\
\hline ApoB (g/l) & $0.87 \pm 0.22$ & $0.88 \pm 0.21^{\mathrm{a}}$ & $0.99 \pm 0.25^{\mathrm{b}, \mathrm{c}}$ & $0.84 \pm 0.21$ & $0.91 \pm 0.22^{\mathrm{e}}$ & $1.02 \pm 0.24^{\mathrm{e}, \mathrm{f}}$ & $0.83 \pm 0.23$ \\
\hline
\end{tabular}

Data are means $\pm \mathrm{SD}$ or median (interquartile range)

eGFR is given in $\mathrm{ml} \mathrm{min}^{-1} 1.73 \mathrm{~m}^{-2}$

All data are adjusted for age, sex and BMI. Patients with lipid-lowering agents were excluded from the analyses

${ }^{\mathrm{a}} p<0.01,{ }^{\mathrm{b}} p<0.001$ vs eGFR $>90 ;{ }^{\mathrm{c}} p<0.001$ vs eGFR $60-90 ;{ }^{\mathrm{d}} p<0.01,{ }^{\mathrm{e}} p<0.001$ vs normal AER; ${ }^{\mathrm{f}} p<0.001$ vs microalbuminuria

higher LDL- and $\mathrm{HDL}_{2}$-cholesterol, and lower total HDLand $\mathrm{HDL}_{3}$-cholesterol $(p<0.001$ for all) than the control group.

To study factors associated with eGFR, multiple linear regression analysis was performed. The model included variables that were significantly associated with eGFR in univariate analyses. Some lipid variables were intercorrelated and could not be included in the same model. Age, BMI, triacylglycerol and systolic blood pressure were independently associated with eGFR $\left(R^{2}=0.28\right.$; Table 3$)$. LDL- and HDLcholesterol were not independently associated with eGFR. When HDL-cholesterol was replaced by ApoA-I the model remained unchanged and ApoA-I was also not independently associated with estimated GFR. When triacylglycerol and LDL were replaced with ApoB, ApoB was independently associated with eGFR $\left(R^{2}=0.28\right)$. When AER was added to the original model, systolic blood pressure and triacylglycerol

Table 3 Factors associated with eGFR in a multiple linear regression

\begin{tabular}{lllll}
\hline Estimated GFR & $B$ & SE & $\beta$ & $p$ value \\
\hline Age (years) & -1.17 & 0.05 & -0.46 & $<0.001$ \\
BMI $\left(\mathrm{kg} / \mathrm{m}^{2}\right)$ & 2.18 & 0.15 & 0.26 & $<0.001$ \\
lnTriacylglycerol & -6.11 & 1.19 & -0.09 & $<0.001$ \\
Systolic blood pressure (mmHg) & -0.12 & 0.03 & -0.07 & $<0.001$ \\
\hline
\end{tabular}

$R^{2}=0.28$

The model also included: LDL- and HDL-cholesterol

Patients with lipid-lowering agents were excluded from the analyses

$B$, unstandardised regression coefficient were no longer independent predictors of eGFR, but HDLcholesterol became one $\left(R^{2}=0.37\right)$.

The relationship between renal function and AER Among patients with normal AER only $2.3 \%(n=43)$ had impaired renal function, $32.4 \%(n=619)$ mildly impaired and $63.7 \%$ $(n=1,248)$ normal renal function. The normoalbuminuric patients with impaired renal function were predominantly women, of higher age and had a longer duration of diabetes, higher systolic blood pressure, lower diastolic blood pressure and normal weight (data not shown). The proportion of patients with impaired renal function in the patient groups with microalbuminuria and macroalbuminuria was 5.9 and $50.4 \%$ respectively. On the other hand, among patients with impaired renal function $13.4 \%(n=43)$ had normal AER, $8.1 \%(n=26)$ had microalbuminuria and $78.5 \%(n=252)$ had macroalbuminuria.

Lipid profile by albuminuria Associations between lipid profiles and albuminuria are shown in Table 2. Multiple linear regression analysis was performed in order to study factors associated with AER. The model included variables that were significantly associated with AER in univariate analyses. Systolic blood pressure, $\mathrm{HbA}_{1 \mathrm{c}}$, triacylglycerol, duration of diabetes and both HDL- and LDL-cholesterol were independently associated with AER $\left(R^{2}=0.23\right.$; Table 4$)$. When triacylglycerol and LDL-cholesterol were replaced with ApoB in the model, ApoB was also an independent predictor of AER $\left(R^{2}=0.23\right)$. HDL-cholesterol was also replaced with 
Table 4 Factors associated with AER in a multiple linear regression

\begin{tabular}{lllll}
\hline LnAER & $B$ & SE & $\beta$ & $p$ value \\
\hline $\begin{array}{l}\text { Systolic blood pressure } \\
(\mathrm{mmHg})\end{array}$ & 0.02 & 0.002 & 0.22 & $<0.001$ \\
$\mathrm{HbA}_{1 \mathrm{c}}(\%)$ & 0.22 & 0.02 & 0.19 & $<0.001$ \\
Diabetes duration (years) & 0.02 & 0.003 & 0.17 & $<0.001$ \\
lnTriacylglycerol & 0.65 & 0.08 & 0.17 & $<0.001$ \\
HDL-cholesterol (mmol/l) & -0.28 & 0.10 & -0.06 & $<0.01$ \\
LDL-cholesterol (mmol/1) & 0.08 & 0.04 & 0.04 & $<0.05$ \\
\hline
\end{tabular}

$R^{2}=0.23$

Patients with lipid-lowering agents were excluded from the analyses $B$, unstandardised regression coefficient

ApoA-I, but ApoA-I was not an independent predictor of AER. When eGFR was added to the original model, LDL-cholesterol was no longer an independent predictor of AER, but the other variables (systolic blood pressure, $\mathrm{HbA}_{1 \mathrm{c}}$, triacylglycerol, diabetes duration and HDL-cholesterol) stayed significant $\left(R^{2}=0.27\right)$.

Lipid profile and glycaemic control, obesity and hypertension in patients without manifest renal disease To assess the impact of glycaemic control, obesity and hypertension on the lipid profile in participants without manifest renal disease, we studied patients with normal AER and with an
eGFR $>60 \mathrm{ml} \mathrm{min}^{-1} 1.73 \mathrm{~m}^{-2}$ (Table 5). There were clear differences between all three groups of glycaemic and weight control. Patients with intermediate glycaemic control had higher total cholesterol, LDL-cholesterol and ApoB concentrations than patients with good glycaemic control $(p<$ 0.01 for all). In addition, patients with poor glycaemic control had higher total cholesterol $(p<0.001)$, LDL-cholesterol $(p<$ $0.01)$, triacylglycerol $(p<0.001)$ and ApoB $(p<0.001)$, as well as lower $\mathrm{HDL}_{2}$-cholesterol $(p<0.01)$ concentrations than patients with intermediate glycaemic control. Patients who were overweight had higher total and LDL-cholesterol, triacylglycerol and $\mathrm{ApoB}$, as well as lower $\mathrm{HDL}_{2}$-cholesterol than patients with normal weight $(p<0.001$ for all). Hypertension was also associated with higher total cholesterol, LDL-cholesterol and ApoB levels $(p<0.01$ for all).

Prevalence of patients that would have achieved the targets of international guidelines of year 2007 In general, treatment targets recommended by international guidelines on HDL-cholesterol and triacylglycerol would have been achieved more often than the targets for LDL-cholesterol (Table 6). Of patients with impaired renal function, macroalbuminuria or obesity without renal disease less than $18 \%$ would have reached the targets for LDL-cholesterol, less than 55\% the targets for HDL-cholesterol and less than 75\% that for triacylglycerol. In patients without renal disease only

Table 5 The lipid profiles of patients without manifest renal disease subdivided by $\mathrm{HbA}_{1 \mathrm{C}}$, BMI and hypertension

\begin{tabular}{|c|c|c|c|c|c|c|c|c|}
\hline & \multicolumn{3}{|l|}{$\mathrm{HbA}_{1 \mathrm{C}}(\%)$} & \multicolumn{5}{|l|}{ BMI $\left(\mathrm{kg} / \mathrm{m}^{2}\right)$} \\
\hline & $<7.5$ & $7.5-9.0$ & $>9.0$ & $<25$ & $25-30$ & $>30$ & $\begin{array}{l}\text { No } \\
\text { hypertension }\end{array}$ & Hypertension \\
\hline$N$ & 499 & 807 & 430 & 1,023 & 627 & 120 & 801 & 962 \\
\hline $\begin{array}{l}\text { Total cholesterol } \\
(\mathrm{mmol} / \mathrm{l})\end{array}$ & $4.63 \pm 0.87$ & $4.80 \pm 0.86^{\mathrm{a}}$ & $4.96 \pm 0.93^{\mathrm{b}, \mathrm{d}}$ & $4.67 \pm 0.83$ & $4.94 \pm 0.94^{f}$ & $5.12 \pm 0.88^{f}$ & $4.66 \pm 0.83$ & $4.91 \pm 0.92^{\mathrm{i}}$ \\
\hline $\begin{array}{l}\text { LDL-cholesterol } \\
(\mathrm{mmol} / \mathrm{l})\end{array}$ & $2.81 \pm 0.79$ & $2.99 \pm 0.79^{\mathrm{a}}$ & $3.08 \pm 0.85^{\mathrm{c} \mathrm{b}}$ & $2.84 \pm 0.75$ & $3.10 \pm 0.87^{\mathrm{f}}$ & $3.29 \pm 0.79^{\mathrm{f}}$ & $2.84 \pm 0.75$ & $3.07 \pm 0.84^{\mathrm{i}}$ \\
\hline $\begin{array}{l}\text { HDL-cholesterol } \\
(\mathrm{mmol} / \mathrm{l})\end{array}$ & $1.35 \pm 0.37$ & $1.34 \pm 0.36$ & $1.30 \pm 0.37$ & $1.36 \pm 0.36$ & $1.31 \pm 0.36^{\mathrm{f}}$ & $1.22 \pm 0.31^{\mathrm{f}, \mathrm{g}}$ & $1.33 \pm 0.36$ & $1.33 \pm 0.36$ \\
\hline $\begin{array}{l}\mathrm{HDL}_{2} \text {-cholesterol } \\
(\mathrm{mmol} / \mathrm{l})\end{array}$ & $0.58 \pm 0.25$ & $0.56 \pm 0.26$ & $0.51 \pm 0.24^{\mathrm{a}, \mathrm{c}}$ & $0.58 \pm 0.26$ & $0.53 \pm 0.25^{\mathrm{f}}$ & $0.44 \pm 0.22^{\mathrm{f}, \mathrm{h}}$ & $0.56 \pm 0.25$ & $0.55 \pm 0.26$ \\
\hline $\begin{array}{l}\mathrm{HDL}_{3} \text {-cholesterol } \\
(\mathrm{mmol} / \mathrm{l})\end{array}$ & $0.78 \pm 0.20$ & $0.78 \pm 0.18$ & $0.80 \pm 0.20$ & $0.79 \pm 0.19$ & $0.78 \pm 0.20$ & $0.79 \pm 0.17$ & $0.78 \pm 0.19$ & $0.79 \pm 0.19$ \\
\hline $\begin{array}{l}\text { Triacylglycerol } \\
(\mathrm{mmol} / \mathrm{l})\end{array}$ & $\begin{array}{l}0.87 \\
(0.67-1.17)\end{array}$ & $\begin{array}{l}0.93 \\
(0.73-1.26)\end{array}$ & $\begin{array}{l}1.07 \\
(0.81-1.49)^{\mathrm{b}, \mathrm{d}}\end{array}$ & $\begin{array}{l}0.88 \\
(0.68-1.21)\end{array}$ & $\begin{array}{l}1.00 \\
(0.78-1.37)^{\mathrm{f}}\end{array}$ & $\begin{array}{l}1.17 \\
(0.86-1.68)^{\mathrm{f}, \mathrm{g}}\end{array}$ & $\begin{array}{l}0.92 \\
(0.70-1.28)\end{array}$ & $\begin{array}{l}0.96 \\
(0.75-1.29)\end{array}$ \\
\hline ApoA-I (g/l) & $1.38 \pm 0.21$ & $1.39 \pm 0.22$ & $1.39 \pm 0.23$ & $1.39 \pm 0.22$ & $1.38 \pm 0.22$ & $1.35 \pm 0.20^{\mathrm{e}}$ & $1.38 \pm 0.21$ & $1.40 \pm 0.22^{\mathrm{i}}$ \\
\hline ApoA-II (g/l) & $0.33 \pm 0.09$ & $0.33 \pm 0.09$ & $0.35 \pm 0.09^{\mathrm{b}, \mathrm{c}}$ & $0.33 \pm 0.09$ & $0.34 \pm 0.09^{f}$ & $0.35 \pm 0.08^{\mathrm{e}}$ & $0.32 \pm 0.08$ & $0.34 \pm 0.09^{\mathrm{i}}$ \\
\hline ApoB (g/l) & $0.79 \pm 0.20$ & $0.84 \pm 0.20^{\mathrm{a}}$ & $0.90 \pm 0.21^{\mathrm{b}, \mathrm{d}}$ & $0.80 \pm 0.19$ & $0.88 \pm 0.21^{\mathrm{f}}$ & $0.97 \pm 0.21^{\mathrm{f}, \mathrm{h}}$ & $0.81 \pm 0.20$ & $0.87 \pm 0.21^{\mathrm{i}}$ \\
\hline
\end{tabular}

Data are means \pm SD or median (interquartile range)

Data for $\mathrm{HbA}_{1 \mathrm{c}}$ and hypertension are adjusted for age, sex and BMI, data for BMI are adjusted for age and sex. Patients with lipid-lowering agents, AER $>20 \mu \mathrm{g} / \mathrm{min}$ or $>30 \mathrm{mg} / 24 \mathrm{~h}$ or estimated GFR $<60 \mathrm{ml} \mathrm{min}{ }^{-1} 1.73 \mathrm{~m}^{-1}$ were excluded from the analyses

${ }^{\mathrm{a}} p<0.01,{ }^{\mathrm{b}} p<0.001 \mathrm{vs} \mathrm{HbA} 1 \mathrm{c}<7.5 \% ;{ }^{\mathrm{c}} p<0.01,{ }^{\mathrm{d}} p<0.001 \mathrm{vs} \mathrm{HbA}_{1 \mathrm{c}} 7.5-9.0 \%$; ${ }^{\mathrm{e}} p<0.01,{ }^{\mathrm{f}} p<0.001 \mathrm{vs} \mathrm{BMI}<25 \mathrm{~kg} / \mathrm{m}^{2} ;{ }^{\mathrm{g}} p<0.01,{ }^{\mathrm{h}} p<0.001 \mathrm{vs}$ BMI $25-30 \mathrm{~kg} / \mathrm{m}^{2} ;{ }^{\mathrm{i}} p<0.01$ vs no hypertension 
Table 6 Prevalence of patients with characteristics as listed, who would have achieved recommended targets
Values are $\%$

Patients with lipid-lowering agents were excluded from the analyses

${ }^{a}$ American Diabetes Association recommendations: see [12]

\begin{tabular}{|c|c|c|c|}
\hline \multirow[t]{2}{*}{ Characteristics } & \multicolumn{3}{|c|}{ Recommended targets $^{\mathrm{a}}$} \\
\hline & $\begin{array}{l}\text { LDL-cholesterol } \\
<2.6 \mathrm{mmol} / 1\end{array}$ & $\begin{array}{l}\text { HDL-cholesterol } \\
>1.0 \mathrm{mmol} / 1 \text { for men, } \\
>1.3 \mathrm{mmol} / 1 \text { for women }\end{array}$ & $\begin{array}{l}\text { Triacylglycerol } \\
<1.7 \mathrm{mmol} / 1\end{array}$ \\
\hline \multicolumn{4}{|l|}{ All patients } \\
\hline eGFR >90 & 34.8 & 64.6 & 83.3 \\
\hline eGFR 60-90 & 26.8 & 71.6 & 88.0 \\
\hline eGFR $<60$ & 17.1 & 53.5 & 68.4 \\
\hline Normal AER & 34.6 & 68.7 & 87.4 \\
\hline Microalbuminuria & 27.8 & 68.4 & 80.8 \\
\hline Macroalbuminuria & 14.1 & 52.2 & 68.1 \\
\hline \multicolumn{4}{|c|}{ Patients without renal disease } \\
\hline $\mathrm{HbA}_{1 \mathrm{c}}<7.5 \%$ & 42.9 & 71.3 & 89.4 \\
\hline $\mathrm{HbA}_{1 \mathrm{c}} 7.5-9.0 \%$ & 32.7 & 69.1 & 89.1 \\
\hline $\mathrm{HbA}_{1 \mathrm{c}}<9.0 \%$ & 30.5 & 62.6 & 81.6 \\
\hline $\mathrm{BMI}<25 \mathrm{~kg} / \mathrm{m}^{2}$ & 40.5 & 71.7 & 91.2 \\
\hline BMI $25-30 \mathrm{~kg} / \mathrm{m}^{2}$ & 29.1 & 65.4 & 83.6 \\
\hline $\mathrm{BMI}>30 \mathrm{~kg} / \mathrm{m}^{2}$ & 17.8 & 55.0 & 75.0 \\
\hline No hypertension & 41.3 & 66.2 & 88.8 \\
\hline Hypertension & 29.7 & 70.1 & 86.3 \\
\hline
\end{tabular}

about $40 \%$ would have achieved the target for LDLcholesterol, even if they had good glycaemic control, normal weight or were normotensive. Since current guidelines were not in practice all the time the data were collected, we also looked at how many patients would have exceeded less stringent criteria for LDL-cholesterol $(<3 \mathrm{mmol} / \mathrm{l})$ and still found that $51 \%$ of all patients would have exceeded this target (data not shown). Although HDL-cholesterol and triacylglycerol targets would have been more easily achieved, the percentages of patients that would have achieved the recommended concentrations decreased with worsening glycaemic control, body weight and albuminuria.

\section{Discussion}

In this large Finnish multicentre study we report for the first time that the lipid profiles of patients with type 1 diabetes are not only closely related to albuminuria, but also to renal function. Importantly, less than $18 \%$ of the patients with impaired renal function, macroalbuminuria or obesity without renal disease would have achieved the target of $<2.6 \mathrm{mmol} / 1$ recommended by international guidelines for LDL-cholesterol. Although HDL-cholesterol and triacylglycerol would have been more easily targeted, the number of patients that would have achieved the recommended targets decreased with worsening glycaemic control, increased body weight, hypertension and albuminuria.

We have previously reported in a smaller study that patients with type 1 diabetes and various degrees of albuminuria display multiple lipid abnormalities [5]. This current large-scale study replicated these findings and extended the association to various degrees of renal function. Importantly, we observed an increased frequency of patients with LDLcholesterol above $2.6 \mathrm{mmol} / \mathrm{l}$ in parallel with the severity of kidney disease. This raises the possibility that elevated LDL-cholesterol contributes to the increased risk of macrovascular disease in this patient group as seen in other highrisk populations. Microalbuminuria and serum creatinine, both indicators of renal disease, are risk factors for cardiovascular disease $[14,15]$. The combination of proteinuria and reduced GFR has also been associated with a substantial increase in cardiovascular and all-cause mortality in the Japanese general population [16]. In our study we observed that $2.3 \%$ of patients with normal AER had impaired renal function and $13.4 \%$ of patients with impaired renal function had normal AER. In a recent study in patients with type 2 diabetes in whom GFR was estimated using the modification of diet in renal disease (MDRD) formula, as many as $42 \%$ of patients with impaired renal function had a normal AER. This discrepancy, however, is most likely to be due to differences in the type of diabetes, as well as to age and methodology. Studies in patients with type 1 diabetes have yielded conflicting results. Some studies have not found a reduced GFR at all in patients with normal AER [17], while others have $[10,18]$.

The patients studied $(n=2,927)$ account for roughly $10 \%$ of all patients with type 1 diabetes in Finland and were evenly distributed all over the country. Thus, this cohort is unique for the study of lipid profiles of patients with type 1 diabetes from several angles, since selection bias is less likely than in single hospital-based studies. Further, all lipid 
variables were measured in the same laboratory specialised in lipid research. One limitation, however, is that we did not measure GFR directly. The Cockcroft-Gault formula [13] was originally developed in a population that consisted of hospitalised men. It was reported to be reasonably accurate in patients with a GFR $<60 \mathrm{ml} \mathrm{m^{-1 }} 1.73 \mathrm{~m}^{-2}$, but less accurate when GFR is within the normal range. To date, unfortunately, there is no optimal non-invasive method to estimate early changes in renal function. The MDRD equation [19] tends to overestimate the number of patients with impaired renal function, while the Cockcroft-Gault formula overestimates the actual renal function because the estimate also includes the tubular secretion of creatinine [20].

The effect of impaired renal function on the lipid profile seems to be similar to that of increased AER and also dependent on the presence of albuminuria. Thus, patients with impaired renal function displayed an atherogenic lipid profile with high total cholesterol, LDL-cholesterol, triacylglycerol and $\mathrm{ApoB}$, and also low HDL-cholesterol concentrations. In our multiple linear regression models, triacylglycerol was a stronger predictor of eGFR and AER than LDL-or HDLcholesterol. Apolipoproteins on the other hand did not provide any additional information that was not gained from triacylglycerol, LDL- or HDL-cholesterol data. In patients without diabetes, impaired renal function has also been associated with increased triacylglycerol and VLDL-cholesterol concentrations [21, 22]. Decreased levels of HDL-cholesterol have also been reported [22], but in contrast to our findings, changes in LDL-cholesterol and ApoB with impairment of renal function have been insignificant [21, 22]. Importantly, a third of our patients with normal AER had mildly impaired renal function and $2 \%$ had impaired renal function. It has previously been shown that patients with type 2 diabetes and a reduced eGFR (calculated by MDRD6 formula) have a similar degree of intrarenal vascular damage irrespective of their AER status [23]. Likewise, a decline in renal function has been reported to be associated with an increase in carotid intimalmedial thickness and an increase in intrarenal arterial resistance index [24]. Thus, not only AER, but also GFR may be a marker of generalised vascular disease. Moreover, more advanced glomerular lesions have been found in patients with type 1 diabetes and normal AER who had a reduced GFR than in patients with normal AER and normal renal function [10].

The effect of glycaemic control on the lipid profiles was studied in patients without manifest renal disease. The differences were most apparent between patients with intermediate and poor glycaemic control. Earlier studies in patients with normal AER have been limited by rather small numbers of patients and have only reported effects of glycaemic control on HDL- and VLDL-cholesterol [25]. Total cholesterol, LDL- and HDL-cholesterol, triacylglycerol and ApoB were independently associated with $\mathrm{HbA}_{1 \mathrm{c}}$ in studies including patients with various degrees of kidney disease [26, 27].
However, these observations may have been biased by the inclusion of patients with renal disease, which in itself is associated with worse glycaemic control and dyslipidaemia. When we divided the patients without manifest renal disease into three groups according to glycaemic control, total cholesterol, LDL-cholesterol and ApoB were elevated when $\mathrm{HbA}_{1 \mathrm{c}}$ exceeded 7.5\%, while triacylglycerol and HDLcholesterol did not change significantly with $\mathrm{HbA}_{1 \mathrm{c}}$ below $9.0 \%$. These observations may partly be explained by glycation of lipids and lipoproteins in diabetic patients with poor glycaemic control. Glycation may slow down the catabolism of low-density lipoproteins [28] and might enhance the transfer of cholesteryl esters from HDL to ApoB-containing lipoproteins [29]. In contrast, type 1 diabetic patients with good glycaemic control have elevated HDL-cholesterol [30-32]. This may be due to the stimulation of lipoprotein lipase activity by insulin [33], which in turn may lead to compositional alterations of HDL-cholesterol that may not be protective against atherosclerosis [34].

There were clear differences in the lipid profiles by BMI. Interestingly, the impact of BMI in patients without manifest renal disease existed not only in obese, but also in overweight (BMI $25-30 \mathrm{~kg} / \mathrm{m}^{2}$ ) participants. Total cholesterol, LDLcholesterol, triacylglycerol and $\mathrm{ApoB}$ concentrations were increased, whereas total HDL- and $\mathrm{HDL}_{2}$-cholesterol were decreased with increasing BMI. Excessive weight gain together with intensive insulin therapy in the DCCT study resulted in higher total cholesterol, triacylglycerol, LDLcholesterol and ApoB, as well as lower HDL-cholesterol and ApoA-I levels, despite the improvement in glycaemic control. The beneficial effect of improved glycaemic control on the lipid profile was seen only in patients with a modest weight gain [35]. One possible explanation for these adverse changes in the lipid profile in obese patients is that levels of NEFA, released from adipose tissue, are increased due to the increased mass of adipose tissue. Higher levels of NEFA in turn lead to increased hepatic triacylglycerol and cholesterol synthesis, and an increased rate of VLDL particle secretion [34].

Cardiovascular mortality has declined in the general population but the decrease in mortality is less pronounced in diabetic patients [36]. Indeed, among type 1 diabetic patients, cardiovascular disease is still the most common cause of death [37]. Importantly, our data suggest that many patients with type 1 diabetes are in need of lipid-lowering treatment. Today's treatment targets are more strict than they were during the time our patients were studied, which could partly explain the high proportion of patients not achieving the 'modern targets'. On the other hand, even with less stringent criteria for LDL-cholesterol $(<3.0 \mathrm{mmol} / \mathrm{l})$, the majority of the diabetic patients $(51 \%)$ would not have reached the targets. In this study, all patient groups, especially those with micro- or macroalbuminuria or those with 
a decline in renal function, had elevated LDL-cholesterol concentrations in comparison with non-diabetic control persons. In addition, the number of patients who would have achieved the targets of international guidelines decreased in patients who were overweight or had intermediate or poor glycaemic control or hypertension. The largest primary prevention trial including patients with type 1 diabetes is the Heart Protection Study [38], which showed that patients with type 1 diabetes gain the same benefit from lipidlowering treatment as do patients with type 2 diabetes. Given the increased cardiovascular risk in patients with type 1 and type 2 diabetes, as well as the fact that the observed reduction in vascular events was of the same magnitude regardless of baseline cholesterol, it seems justified and would most probably be cost-effective to prescribe lipid-lowering treatment to these high-risk patients. It is noteworthy that atherogenic compositional changes in these patients may exist despite their having normal cholesterol concentrations.

In conclusion, multiple lipid abnormalities are present not only in patients with type 1 diabetes who have an abnormal albumin excretion rate, but also in those with impaired renal function. The degree of obesity, glycaemic control and presence of hypertension were associated with an adverse lipid profile in patients without manifest renal disease. A substantial number of patients in this study would have exceeded the targets set by international guidelines, a finding that was particularly evident for LDL-cholesterol concentrations. Prospective studies are needed to evaluate whether the observed lipid abnormalities play a role in the progression of diabetic nephropathy.

Acknowledgements The study was supported by the Folkhälsan Research Foundation, Samfundet Folkhälsan, Wilhelm and Else Stockmann Foundation, Sigrid Juselius Foundation, Liv och Hälsa Foundation, Perklén Foundation, Waldemar von Frenckell Foundation, the Finnish Medical Society (Finska Läkaresällskapet) and the European Commission (QLG2-CT-2001-01669). The skilled technical assistance of our laboratory technicians S. Lindh, A. Sandelin, H. Hilden, H. Perttunen-Mio, V. Naatti, S. Ström and J. Thorn is gratefully acknowledged. Finally, we acknowledge the physicians and nurses at each study centre, details of whom are presented in the Electronic supplementary material (ESM).

Duality of interest The authors declare that there is no duality of interest associated with this manuscript.

\section{References}

1. Borch-Johnsen K, Kreiner S (1987) Proteinuria: value as predictor of cardiovascular mortality in insulin dependent diabetes mellitus. BMJ (Clin Res Ed) 294:1651-1654

2. Tuomilehto J, Borch-Johnsen K, Molarius A et al (1998) Incidence of cardiovascular disease in type 1 (insulin-dependent) diabetic subjects with and without diabetic nephropathy in Finland. Diabetologia 41:784-790
3. Gerstein HC, Mann JF, Yi Q et al (2001) Albuminuria and risk of cardiovascular events, death, and heart failure in diabetic and nondiabetic individuals. JAMA 286:421-426

4. Chen Z, Peto R, Collins R, MacMahon S, Lu J, Li W (1991) Serum cholesterol concentration and coronary heart disease in population with low cholesterol concentrations. BMJ 303:276-282

5. Groop PH, Elliott T, Ekstrand A et al (1996) Multiple lipoprotein abnormalities in type I diabetic patients with renal disease. Diabetes 45:974-979

6. Jones SL, Close CF, Mattock MB, Jarrett RJ, Keen H, Viberti GC (1989) Plasma lipid and coagulation factor concentrations in insulin dependent diabetics with microalbuminuria. BMJ 298:487-490

7. Watts GF, Naumova R, Slavin BM et al (1989) Serum lipids and lipoproteins in insulin-dependent diabetic patients with persistent microalbuminuria. Diabet Med 6:25-30

8. Mattock MB, Cronin N, Cavallo-Perin P et al., EURODIAB IDDM Complications Study (2001) Plasma lipids and urinary albumin excretion rate in type 1 diabetes mellitus: The EURODIAB IDDM complications study. Diabet Med 18:59-67

9. Thomas MC, Rosengård-Bärlund M, Mills V et al (2006) Serum lipids and the progression of nephropathy in type 1 diabetes. Diabetes Care 29:317-322

10. Caramori ML, Fioretto P, Mauer M (2003) Low glomerular filtration rate in normoalbuminuric type 1 diabetic patients: an indicator of more advanced glomerular lesions. Diabetes 52:1036-1040

11. Friedewald WT, Levy RI, Fredrickson DS (1972) Estimation of the concentration of low-density lipoprotein cholesterol in plasma, without use of the preparative ultracentrifuge. Clin Chem 18:499-502

12. American Diabetes Association (2007) Standards of medical care in diabetes-2007. Diabetes Care 30:S4-S41

13. Cockcroft DW, Gault MH (1976) Prediction of creatinine clearance from serum creatinine. Nephron 16:31-41

14. Klausen K, Borch-Johnsen K, Feldt-Rasmussen B et al (2004) Very low levels of microalbuminuria are associated with increased risk of coronary heart disease and death independently of renal function, hypertension, and diabetes. Circulation 110:32-35

15. So WY, Kong AP, Ma RC et al (2006) Glomerular filtration rate, cardiorenal end points, and all-cause mortality in type 2 diabetic patients. Diabetes Care 29:2046-2052

16. Irie F, Iso H, Sairenchi T et al (2006) The relationships of proteinuria, serum creatinine, glomerular filtration rate with cardiovascular disease mortality in Japanese general population. Kidney Int 69:1264-1271

17. Hansen KW, Mau Pedersen M, Christensen CK, Schmitz A, Christiansen JS, Mogensen CE (1992) Normoalbuminuria ensures no reduction of renal function in type 1 (insulin-dependent) diabetic patients. J Intern Med 232:161-167

18. Caramori ML, Gross JL, Pecis M, de Azevedo MJ (1999) Glomerular filtration rate, urinary albumin excretion rate, and blood pressure changes in normoalbuminuric normotensive type 1 diabetic patients: an 8-year follow-up study. Diabetes Care 22: 1512-1516

19. Levey AS, Bosch JP, Lewis JB, Greene T, Rogers N, Roth D (1999) A more accurate method to estimate glomerular filtration rate from serum creatinine: a new prediction equation. Modification of diet in renal disease study group. Ann Intern Med 130:461-470

20. Stevens LA, Coresh J, Greene T, Levey AS (2006) Assessing kidney function-measured and estimated glomerular filtration rate. N Engl J Med 354:2473-2483

21. Grutzmacher P, Marz W, Peschke B, Gross W, Schoeppe W (1988) Lipoproteins and apolipoproteins during the progression of chronic renal disease. Nephron 50:103-111

22. Attman PO, Alaupovic P (1991) Lipid and apolipoprotein profiles of uremic dyslipoproteinemia-relation to renal function and dialysis. Nephron 57:401-410

23. MacIsaac RJ, Panagiotopoulos S, McNeil KJ et al (2006) Is nonalbuminuric renal insufficiency in type 2 diabetes related to an increase in intrarenal vascular disease? Diabetes Care 29:1560-1566 
24. Taniwaki H, Nishizawa Y, Kawagishi T et al (1998) Decrease in glomerular filtration rate in Japanese patients with type 2 diabetes is linked to atherosclerosis. Diabetes Care 21:1848-1855

25. Patti L, Di Marino L, Maffettone A et al (1995) Very low density lipoprotein subfraction abnormalities in IDDM patients: any effect of blood glucose control? Diabetologia 38:1419-1424

26. Jenkins AJ, Lyons TJ, Zheng D et al, DCC/EDIC Research Group (2003) Serum lipoproteins in the diabetes control and complications trial/epidemiology of diabetes intervention and complications cohort: associations with gender and glycemia. Diabetes Care 26:810-818

27. Idzior-Walus B, Mattock MB, Solnica B, Stevens L, Fuller JH, EURODIAB IDDM Complications Study Group (2001) Factors associated with plasma lipids and lipoproteins in type 1 diabetes mellitus: the EURODIAB IDDM Complications Study. Diabetic Med 18:786-796

28. Steinbrecher UP, Witztum JL (1984) Glucosylation of low-density lipoproteins to an extent comparable to that seen in diabetes slows their catabolism. Diabetes 33:130-134

29. Passarelli M, Catanozi S, Nakandakare ER et al (1997) Plasma lipoproteins from patients with poorly controlled diabetes mellitus and 'in vitro' glycation of lipoproteins enhance the transfer rate of cholesteryl ester from HDL to apo-B-containing lipoproteins. Diabetologia 40:1085-1093

30. Nikkilä EA, Hormila P (1978) Serum lipids and lipoproteins in insulin-treated diabetes. Demonstration of increased high density lipoprotein concentrations. Diabetes 27:1078-1086
31. Mattock MB, Salter AM, Fuller JH et al (1982) High density lipoprotein subfractions in insulin-dependent diabetic and normal subjects. Atherosclerosis 45:67-79

32. Durrington PN (1980) Serum high density lipoprotein cholesterol in diabetes mellitus: an analysis of factors which influence its concentration. Clin Chim Acta 104:11-23

33. Taskinen MR (1987) Lipoprotein lipase in diabetes. Diabetes Metab Rev 3:551-570

34. Durrington PN (1999) Diabetic dyslipidaemia. Baillieres Best Pract Res Clin Endocrinol Metab 13:265-278

35. Purnell JQ, Hokanson JE, Marcovina SM, Steffes MW, Cleary PA, Brunzell JD (1998) Effect of excessive weight gain with intensive therapy of type 1 diabetes on lipid levels and blood pressure: results from the DCCT. Diabetes control and complications trial. JAMA 280:140-146

36. Gu K, Cowie CC, Harris MI (1999) Diabetes and decline in heart disease mortality in US adults. JAMA 281:1291-1297

37. Laing SP, Swerdlow AJ, Slater SD et al (1999) The British Diabetic Association Cohort Study, II: cause-specific mortality in patients with insulin-treated diabetes mellitus. Diabet Med 16: 466-471

38. Collins R, Armitage J, Parish S, Sleigh P, Peto R, Heart Protection Study Collaborative Group (2003) MRC/BHF heart protection study of cholesterol-lowering with simvastatin in 5963 people with diabetes: a randomised placebo-controlled trial. Lancet 361 : 2005-2016 